Slavica

bruxellensia

\section{Slavica bruxellensia}

Revue polyphonique de littérature, culture et histoire

slaves

$10 \mid 2014$

Espace slave, espace germanique

\title{
From Your Land to Poland. On the Commitment of Writers
}

\section{Michał Bandura}

Traducteur : Katia Vandenborre

\section{OpenEdition}

\section{Journals}

Édition électronique

URL : http://journals.openedition.org/slavica/1625

DOI : 10.4000/slavica. 1625

ISSN : 2034-6395

\section{Éditeur}

Université libre de Bruxelles - ULB

\section{Référence électronique}

Michał Bandura, «From Your Land to Poland. On the Commitment of Writers », Slavica bruxellensia [En ligne], 10 | 2014, mis en ligne le 15 avril 2014, consulté le 22 septembre 2020. URL : http:// journals.openedition.org/slavica/1625; DOI : https://doi.org/10.4000/slavica.1625

Ce document a été généré automatiquement le 22 septembre 2020.

\section{c) $($ ) $९$}

Les contenus de Slavica bruxellensia sont mis à disposition selon les termes de la Licence Creative Commons Attribution - Pas d'Utilisation Commerciale - Pas de Modification 3.0 France. 


\section{From Your Land to Poland. On the Commitment of Writers}

\section{Michał Bandura}

Traduction : Katia Vandenborre

\section{RÉFÉRENCE}

From Your Land to Poland. On the Commitment of Writers, sous la direction de WalczakDelanois D., Vandenborre K. \& James P.,P. I. E. Peter Lang, Bruxelles, 2013, 228 p. 
1 L'ouvrage From Your Land to Poland. On the Commitment of Writers est le fruit d'une conférence organisée par les polonistes de trois universités belges - l'Université Libre de Bruxelles, Katholieke Universiteit Leuven et Universiteit Gent - en novembre 2011 à l'Université libre de Bruxelles. Les organisateurs y posaient les questions suivantes: l'engagement social et politique des écrivains est-il possible à une époque où les conditions de fonctionnement de la littérature sont dictées par le marché? Si oui, quelles

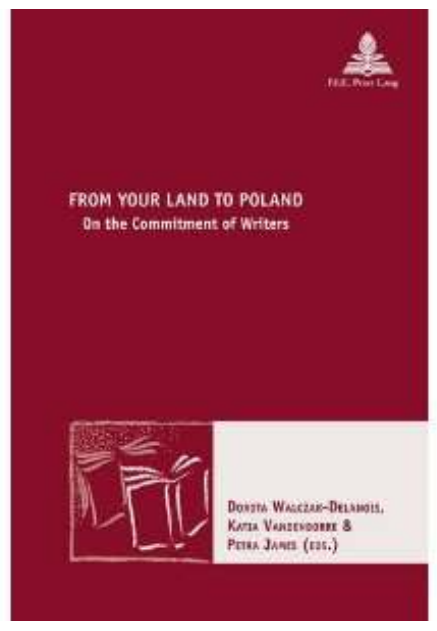
formes peut-il prendre? Quelle influence les actions des artistes peuvent-elles avoir sur la forme des sociétés contemporaines? Enfin, quelle place la littérature occupe-t-elle dans le système actuel de communication? Le matériel de la réflexion devait être avant tout fourni par la littérature polonaise des $\mathrm{xx}^{\mathrm{e}}$ et $\mathrm{XxI}^{\mathrm{e}}$ siècles, mais d'autres accents viennent diversifier le volume, par exemple l'analyse de la figure de Bertrand Russel durant la Première Guerre mondiale par Olivier Estèves ou encore celle de la situation des écrivains arabes en Europe sous la plume de Xavier Luffin.

2 Édité par trois chercheuses de l'ULB - Dorota Walczak-Delanois, Katia Vandenborre et Petra James -, le recueil se compose de trois parties. Le héros de la première est Czesław Miłosz. C’est non seulement à l'œuvre du poète, mais aussi à sa biographie que les auteurs (notamment Aleksander Fiut et Anna Nasiłowska) se réfèrent pour tenter de répondre aux questions qui touchent la condition de la littérature dans la société d'aujourd'hui. L'article de Kris van Heuckelom se distingue dans ce chapitre. Le critique part de l'analyse d'un certain nombre de métaphores, avant tout la chasse et le « cœur de la forêt ${ }^{1}$ mickiewiczien, et en tire des conclusions sur la relation entre le sujet, le « moi » du texte, et l'Autre, le monde extérieur. Ces relations élémentaires constituent un fondement dans la poésie de Miłosz, fondement sur lequel sont construites toutes les références et relations sujet-objet, y compris les jugements de valeur et les positions philosophiques. Le chercheur montre que l'engagement politique ou social n'est pas exclusivement une question de déclaration consciente de l'auteur, mais qu'il résulte au contraire de l'adoption antérieure de prémisses au caractère philosophique. Le caractère politique de la littérature n'est pas seulement une question d'éthique, il relève également de l'épistémologie. En ce qui concerne la pertinence de l'analyse et de l'interprétation des textes littéraires ou la précision de la démonstration, l'article de van Heuckelom n'a pas d'équivalent dans le livre.

3 Dans la deuxième partie consacrée à d'autres écrivains polonais, nous trouvons entre autres la réflexion de Marta Skwara sur l'actualité de Witkacy dans la culture de masse ou encore la comparaison du motif de l'exilé dans la poésie de Zbigniew Herbert et d'Osip Mandel'štam par Arent van Nieukerken. Dorota Walczak-Delanois, quant à elle, explore la position ambigüe de Tadeusz Różewicz au sujet de l'érection de monuments et, plus largement, la production des images des écrivains. Enfin, ces considérations sur la littérature et la culture polonaise sont complétées par une analyse critique du spectacle Transfert! dans la mise en scène de Jan Klata par Agnieszka Szmidt. Cette 
pièce qui a fait couler beaucoup d'encre il y a quelques années abordait le sujet difficile des déplacements des populations polonaise et allemande après la fin de la Deuxième Guerre mondiale.

4 La troisième partie de l'ouvrage contient les voix, témoignages et déclarations des écrivains en personne, parmi lesquels nous trouvons des personnalités aussi variées que la poétesse Meenakshi Bharat originaire d'Inde, Antoine Cassar qui est né à Malte et écrit dans plusieurs langues ou encore le jeune poète polonais Szczepan Kopyt.

5 Le volume From Your Land to Poland a été conçu avant tout pour des lecteurs non polonais, désireux de mieux connaître la littérature et l'art de ce pays. Ses qualités tiennent au fait qu'il réunit les opinions de chercheurs issus de milieux universitaires de différents pays et qu'il offre la possibilité de confronter leurs voix avec celles d'écrivains. La thématique même, autrement dit la place des créateurs dans la société, éveille, comme le montre ce volume, d'inépuisables émotions. Il semble qu'une des principales oppositions influant sur la forme et la dynamique de développement de l'écriture moderne - la littérature engagée versus la littérature autonome - n'a pas perdu de son actualité. Cela signifie-t-il - pour détourner l'expression de Bruno Latour ${ }^{2}$ - que nous n'avons jamais cessé d'être modernes?

\section{NOTES}

1. Mickiewicz A., Pan Tadeusz, traduit du polonais par Roger Legras, L'Âge d'Homme, coll. « Classiques slaves », Lausanne, 1992, p. 106.

2. Latour Br., Nous n'avons jamais été modernes. Essai d'anthropologie symétrique, Éd. La Découverte, coll. « L'armillaire », Paris, 1991, 210 p. 